\title{
Ductile Evaluation and Mechanical Performance of Recycled Aggregate Concrete Using PVA and Steel Fibers
}

\author{
Chun Ho Kim ${ }^{1}$, Nam Wook Kim ${ }^{2, ~ * ~}$ \\ ${ }^{1}$ Department of Civil Engineering, Joongbu University, Goyang, Republic of Korea \\ ${ }^{2}$ Department of Civil and Environmental Engineering, Jeonnam State University, Damyang, Republic of Korea
}

\author{
Email address: \\ nwkim@dorip.ac.kr (N. W. Kim) \\ ${ }^{*}$ Corresponding author
}

\section{To cite this article:}

Chun Ho Kim, Nam Wook Kim. Ductile Evaluation and Mechanical Performance of Recycled Aggregate Concrete Using PVA and Steel Fibers. American Journal of Construction and Building Materials. Vol. 5, No. 1, 2021, pp. 1-9. doi: 10.11648/j.ajcbm.20210501.11

Received: December 14, 2020; Accepted: December 28, 2020; Published: January 15, 2021

\begin{abstract}
In recent years, a high toughness cement composite material (HTCCM) has been developed, which has far more performance than existing fiber reinforced concrete. HTCCM is a composite material made by reinforcing cement-based materials with fibers. It exhibits multiple crack characteristics under bending stress and greatly improves toughness during flexural, tensile, and compressive fracture. In this study, it is examined the mechanical properties of high fluidity and high toughness concrete (HFHTC) using fly ash as an admixture and recycled fine and coarse aggregate as an aggregate. From the standpoint of durability, it is necessary to fully examine the long-term properties of HFHTC using recycled fine and coarse aggregate, therefore, it is examined the strength and shrinkage of HFHTC using recycled fine and coarse aggregates.
\end{abstract}

Keywords: Ductile Evaluation, Mechanical Performance, Recycled Aggregate, Shrinkage Strain, PVA Fiber, Steel Fiber

\section{Introduction}

Many paper and research on recycled aggregate have been actively carried out in the concrete industry. To promote the recycling of concrete more extensively, it is necessary to develop new technology for effectively using recycled aggregate. As an example, research on ductile-fiber-reinforced cementitious composites (DFRCC) using recycled fine aggregate has been reported. DFRCC are composites of cementitious material reinforced with fibers, which have multiple cracking characteristics and much improved toughness during bending, tension, and compression fracture. [1-4]

However, due to workability-related defects and so on, there are only a limited number of examples of construction using DFRCC. If DFRCC with excellent workability characteristics can be developed, those problems would be solved. As this material overcomes the brittle properties of general concrete, the performance and durability of concretebased structural elements are expected to be greatly improved, and various new applications such as high-performance repair materials and shock-absorbing materials are expected to replace conventional cement-based materials. However, although actual examples of construction using DFRCC have been reported, the number is still small. [5-8]

The reasons for this are construction performance problems, high cost compared to other materials, and large effects due to hydration heat and dry shrinkage compared to general concrete because mortar and cement paste are mainly used as matrices. To promote the use of DFRCC in the future, it is considered necessary to develop new materials, including improvements to existing materials. By the way, in implementing production activities, efforts to deal with global environmental problems are an important issue. In the concrete field, research on recycled aggregate concrete, which is used to manufacture concrete again using recycled aggregate taken out of disassembled concrete blocks, is being actively carried out, and research results and construction examples have been reported. To further promote recycling of concrete in the future, it is necessary to develop new effective utilization technologies for recycled aggregate. [9-14]

Therefore, this study focused on high-fluidity concrete, and examined the material properties of high-fluidity ductilefiber-reinforced concrete (HFDFRC) using recycled aggregate. To apply HFDFRC using recycled aggregate (RHFDFRC) to RC structures, it is necessary to clarify the 
long-term material properties (such as strength development and shrinkage behavior) of R-HFDFRC. To evaluate the long-term material properties of R-HFDFRC, we first conducted compressive test, 3-point bending test and shrinkage tests on the R-HFDFRC for materials that had aged 7, 28 and 91 days. Then we tried to apply the approximation formulae which are based on conventional strength development formulae. It is concluded that the overall trend in strength development in R-HFDFRC can be broadly approximated with our equation proposed.

\section{Experimental Outlines}

In this study, uniaxial compression test, 3-point bending test, and shrinkage test of HFDFRC shown in Table 1 were performed, however, RC50P10S0 is a shrinkage test only.

It is also tested the shrinkage of the mortar based DFRCC (DFRM). There are four types of HFDFRC and DFRM: HFDFRC (R-HFDFRC) using recycled fine aggregate, high flow DFRM (R-HFDFRM) using recycled fine aggregate, and high flow DFRM (NHFDFRM) using recycled fine aggregate.

Table 1. Mix proportions of HFDFRC and DFRM.

\begin{tabular}{|c|c|c|c|c|c|c|c|c|}
\hline specimen & Type & Aggregate & $\begin{array}{l}\text { W/B } \\
(\%)\end{array}$ & $\begin{array}{l}\text { s/a } \\
\text { (vol.\%) }\end{array}$ & S/B (\%) & $\begin{array}{l}\text { Fiber volume } \\
\text { fraction (vol. \%) }\end{array}$ & $\begin{array}{l}\text { Fiber volume } \\
\text { mixing ratio }(P ; S)\end{array}$ & $\begin{array}{l}\text { Replacement ratio } \\
\text { of fly ash (\%) }\end{array}$ \\
\hline R-C40P7S3 & concrete & \multirow{8}{*}{$\begin{array}{l}\text { recycled } \\
\text { aggregate }\end{array}$} & 40 & \multirow{4}{*}{85} & 40 & \multirow{9}{*}{3.0} & \multirow{7}{*}{$7: 3$} & \multirow{7}{*}{20} \\
\hline R-C50P7S3 & used & & 50 & & 65 & & & \\
\hline R-C60P7S3 & recycled & & 60 & & 90 & & & \\
\hline R-C50P10S0 & aggregate & & 50 & & 65 & & & \\
\hline R-M40P10S0 & mortar & & 40 & \multirow{5}{*}{100} & 40 & & & \\
\hline R-M50P10S0 & used & & 50 & & 65 & & & \\
\hline R-M60P10S0 & $\begin{array}{l}\text { recycled } \\
\text { aggregate }\end{array}$ & & 60 & & 90 & & & \\
\hline R-M50P10S0NF & $\begin{array}{l}\text { mortar } \\
\text { non } \\
\text { fly ash }\end{array}$ & & 50 & & 65 & & \multirow[t]{2}{*}{ 10:0 } & 0 \\
\hline N-M50P10S0 & $\begin{array}{l}\text { mortar used } \\
\text { natural } \\
\text { aggregate }\end{array}$ & $\begin{array}{l}\text { natural } \\
\text { aggregate }\end{array}$ & 50 & & 65 & & & 20 \\
\hline
\end{tabular}

Table 2. Physical properties of aggregate.

\begin{tabular}{llllll}
\hline Aggregate & & Max. size (mm) & Density $\left(\mathbf{g} / \mathbf{c m}^{\mathbf{3}}\right)$ & Absorption $(\%)$ & Fineness modulus \\
\hline \multirow{3}{*}{ Recycled } & Coarse & 10 & 2.58 & 2.54 & 6.04 \\
& Medium fine & 2.5 & 2.57 & 2.98 & 2.48 \\
& Very fine & 0.6 & 2.55 & 4.07 & 1.20 \\
\multirow{2}{*}{ Natural } & Crushed sand & 2.5 & 2.64 & 1.17 & 2.86 \\
& Standard sand & 1.2 & 2.60 & 2.07 & 1.40 \\
\hline
\end{tabular}

\subsection{Used Materials}

A list of the physical properties of the aggregate used in this study is shown in Table 2.

Cement is used ordinary portland cement (density: 3.16 $\mathrm{g} / \mathrm{cm}^{3}$ ). Used fibers are PVA and steel fibers. And physical properties of PVA fibers $(\mathrm{P})$ are diameter: $0.2 \mathrm{~mm}$, length: 18 mm, elastic modulus: $27 \mathrm{GPa}$, and tensile strength: $975 \mathrm{MPa}$. The physical properties of steel fiber (S) are diameter: 0.55 $\mathrm{mm}$, length: $30 \mathrm{~mm}$, modulus of elasticity: $210 \mathrm{GPa}$, and tensile strength: $114 \mathrm{MPa}$.

Used admixtures are high performance $\mathrm{AE}$ water reducing agents and separation reducing agents and so on.

\subsection{Combinations of Specimen}

In this study, the water binder ratio (W/B) of R-HFDFRC and R-HFDFRM was 40, 50 and $60 \%$. R-C50P10S0, RM50P10S0 and N-M50P10S0 have only 50\% W/B. The fine aggregate ratio was $85 \%$ for R-HFDFRC and $100 \%$ for DFRM.

In addition, the preparation of HFDFRC and DFRM used in this study was determined after many trials.

The mixing of coarse aggregate is aimed at reducing shrinkage caused by dry shrinkage. However, when the aggregate ratio is close to the general concrete level, the RHFDFRC results in material separation and not satisfying the target slump flow.

Therefore, even in the preparation of R-HFDFRC used in this study, the fine aggregate ratio was $85 \%$. For the fibers, $\mathrm{P}$ and $\mathrm{S}$ were used, the fiber volume fraction was $3.0 \%$, and the fiber volume fraction ratio $(\mathrm{P}: \mathrm{S})$ between $\mathrm{P}$ and $\mathrm{S}$ was $7: 3$ and 10:0.

\subsection{Uniaxial Compressive Strength}

The outline of the uniaxial compressive test is shown in Figure 1. The loading was carried out using a 2,000 kN pressure-resistance tester. The test specimen was a cylindrical test specimen of $\Phi 100 \times \times 200 \mathrm{~mm}$. Five factors were manufactured. The measurement items were the load, the longitudinal/lateral strain in the center of the test specimen by the compressometer, and the displacement between the loading plates. 
Each data was taken in using a data logger. The specimen was demolded two days after implantation, and standardized until the test (age 7, 28 and 91).

In addition, compressive fracture energy $(\mathrm{GFc})$ is limited to $3.0 \mathrm{~mm}$ according to plastic deformation.

\subsection{3-point Bending Test}

The outline of the 3-point bending test is shown in Figure 2. The specimen was made into a prismatic specimen measuring $100 \times 100 \times 400 \mathrm{~mm}$, and five of each factor was manufactured. The 3-point bending test was conducted in accordance with JCI specification, and the measurement items were load, deflection, and curvature of the center of the span. Each data was taken in using a data logger.

Also, after the test, the number of cracks generated in the net bending section was visually measured, and in this study, this number was defined as the number of cracks.

In addition, the specimen was demolded two days after implantation, and standardized until the test (age 7, 28 and 91 days). Flexural toughness was evaluated by the following method and the flexural strength was determined by the following formula. [15]

$$
f_{f s}=\frac{P \times L}{b \times h^{2}}
$$

Here, $f_{f s}$ : Flexural strength $(\mathrm{MPa}), P$ : Load $(\mathrm{kN}), L$ : Span $(\mathrm{mm}), b$ : Width in case of fracture, $h$ : Height of fracture section

Fracture toughness is then expressed in terms of flexural toughness coefficient and obtained by the following formula.

$$
f_{f t}=\frac{T}{\delta} \times \frac{L}{b h^{2}}
$$

Here, $f_{f t}$ : Flexural toughness $(\mathrm{MPa}), T$ : Area below curve from origin to $\delta, \delta$ : Deflection at center of span ( $\mathrm{mm})$

In this study, $f_{f t}$ is used as the value when $\delta$ becomes 7.5 $\mathrm{mm}$

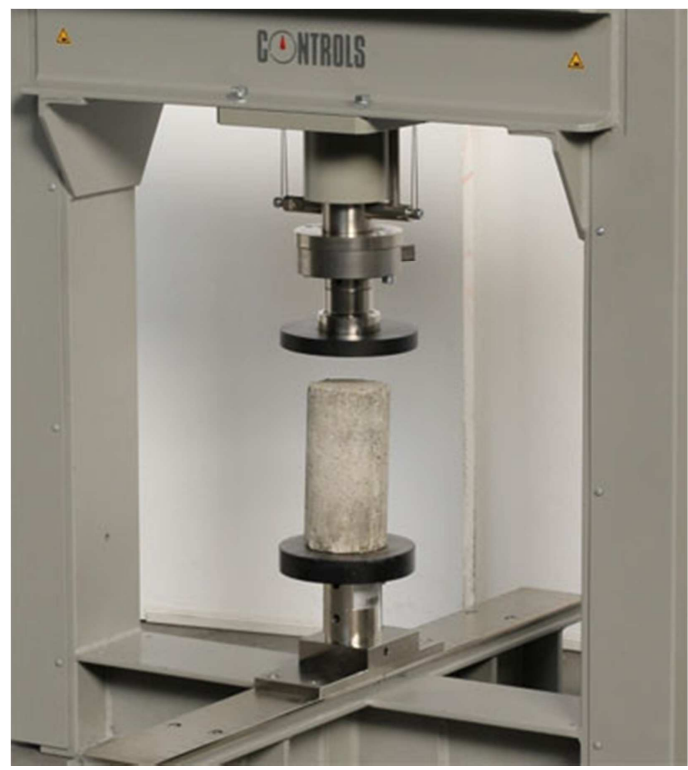

Figure 1. View of compressive loading system.

\subsection{Shrinkage Test}

In this study, it is conducted shrinkage tests for HFDFRC and DFRM with a drying initiation age of 7 days. The specimen was made into a prismatic specimen measuring $100 \times 100 \times 400 \mathrm{~mm}$, and two of each factor was manufactured. Shrinkage strain was measured by installing an embedded strain gauge with a length of $100 \mathrm{~mm}$ in the center of the specimen.

Each data was captured using a data logger, and the test specimen was demolded two days after implantation.

After that, it was standard curing and air curing was performed in a constant temperature and humidity chamber $\left(20^{\circ} \mathrm{C}, 60 \% \mathrm{RH}\right)$ at the age of 7 days.

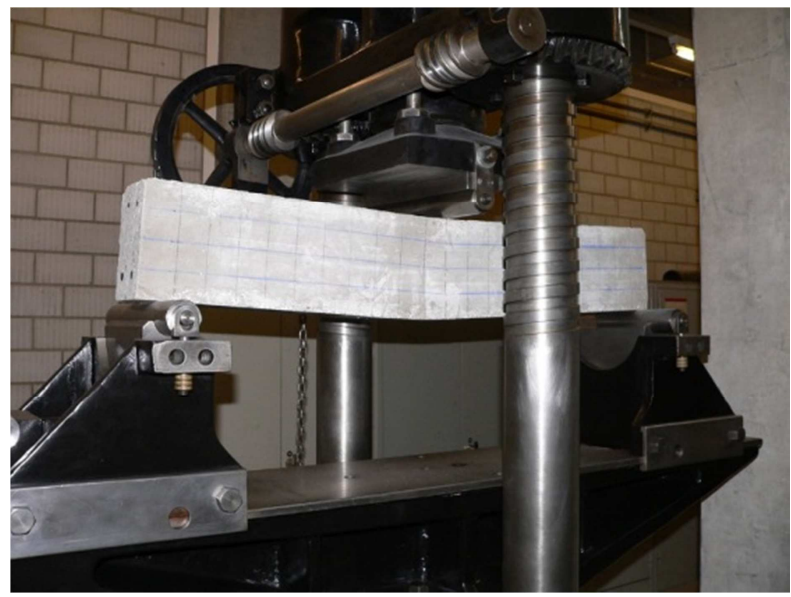

Figure 2. View of 3-point bending test.

\section{Experimental Results and Discussions}

\subsection{Results of Strength Test}

\subsubsection{Compressive Strength}

Figure 3 shows the relationship of compressive strength (Fc), Young's modulus (E), and GFc of R-HFDF up to 91 days obtained by the uniaxial compression test. According to Figure 3, the Fc, E and GFc of R-HFDFRC up to 91 days are increasing with age regardless of the difference in W/B.

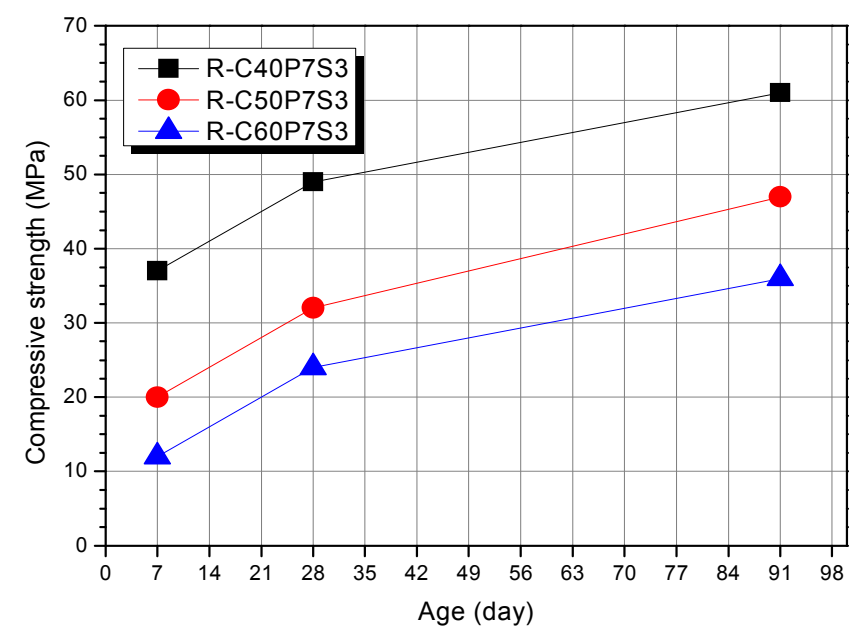

(a) Compressive strength 


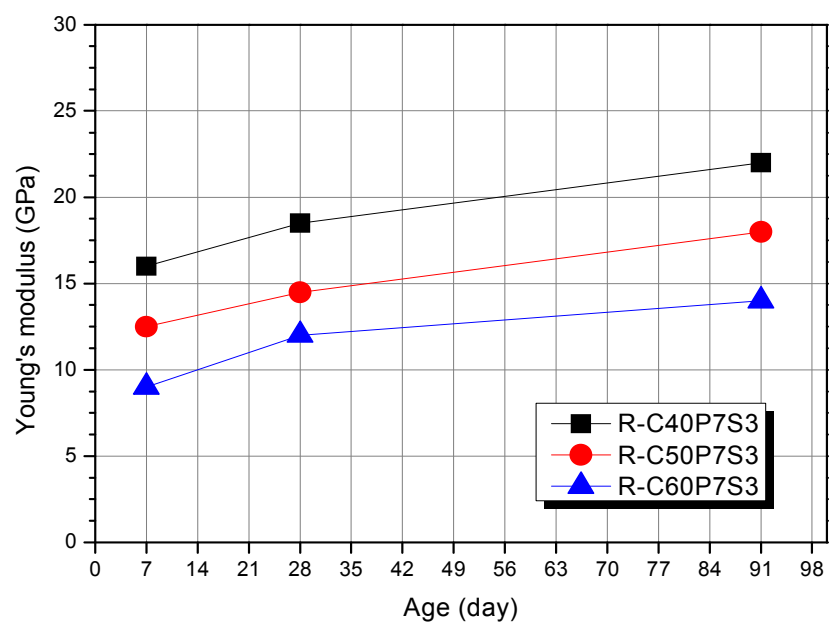

(b) Young's modulus

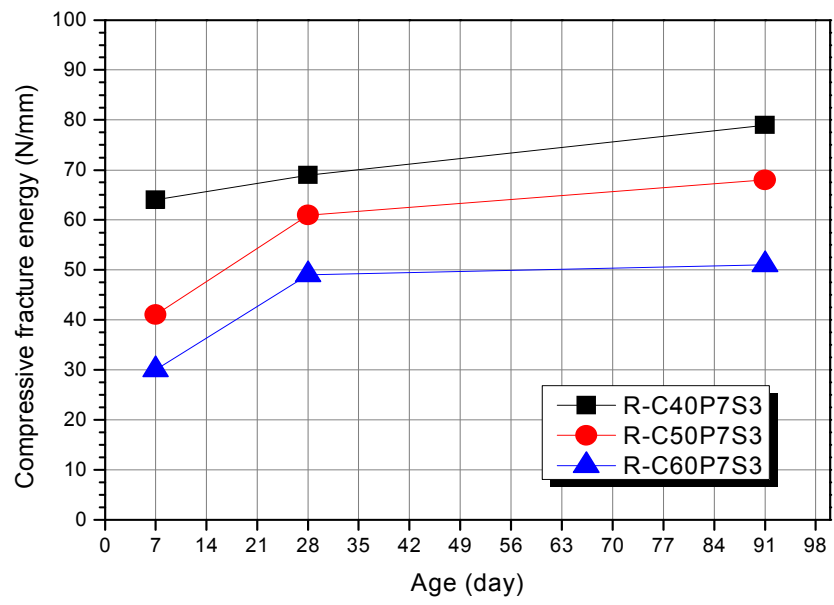

(c) Compressive fracture energy

Figure 3. Relationship of compressive properties and age.

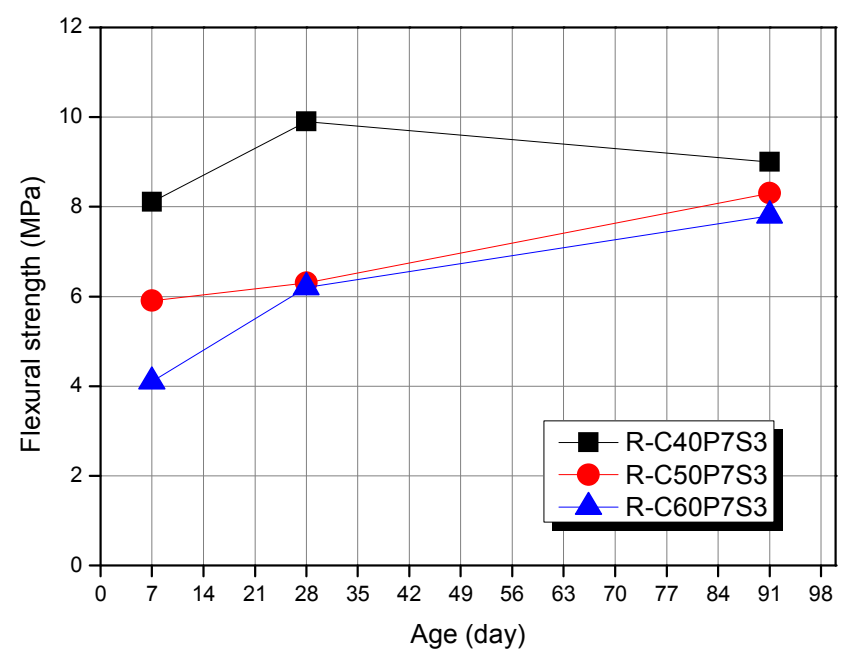

(a) Flexural strength

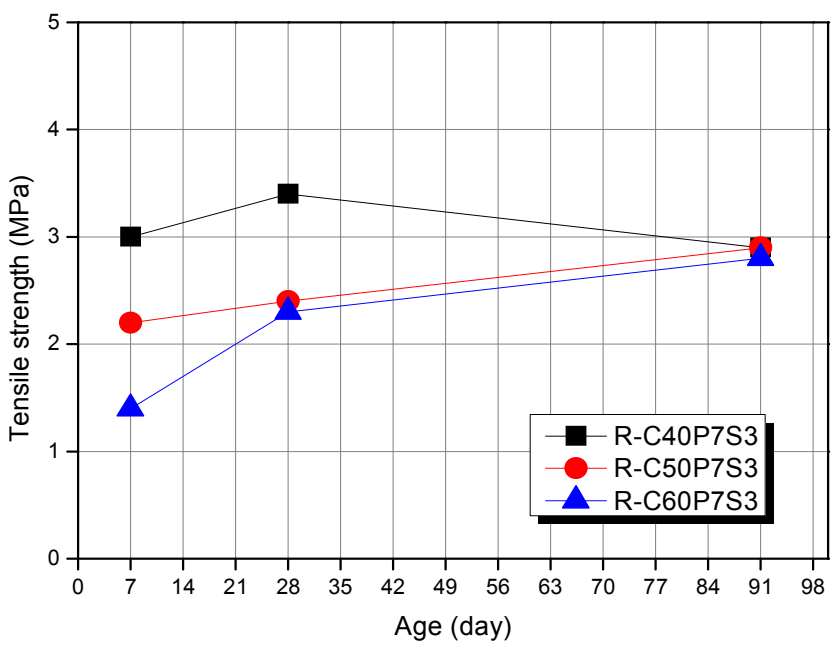

(b) Tensile strength

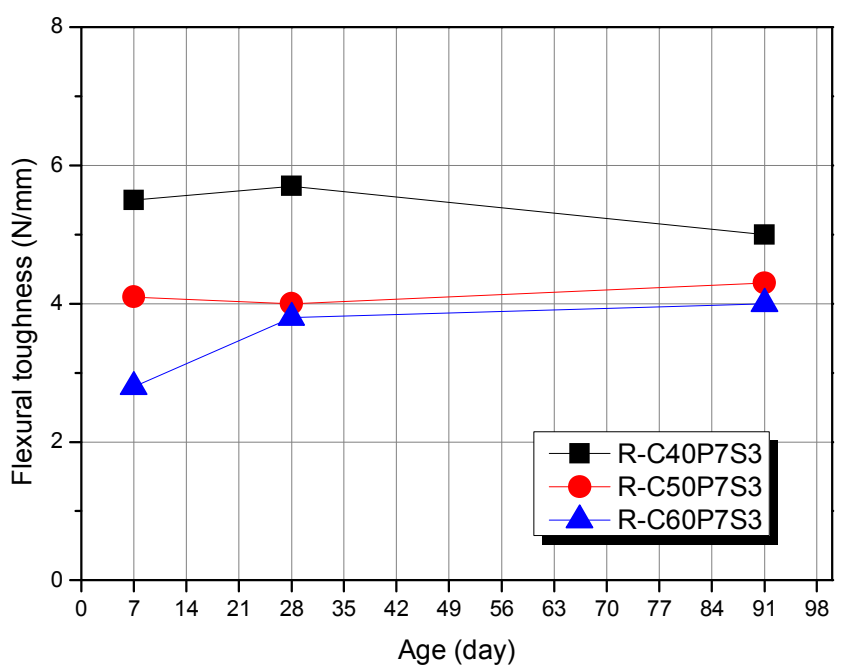

(c) Flexural toughness

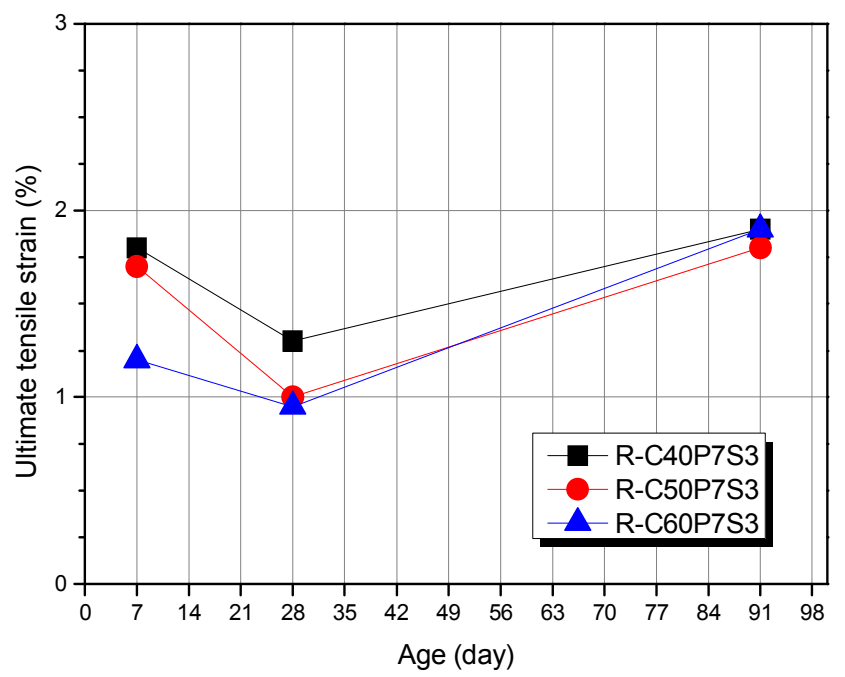

(d) Ultimate tensile strain 


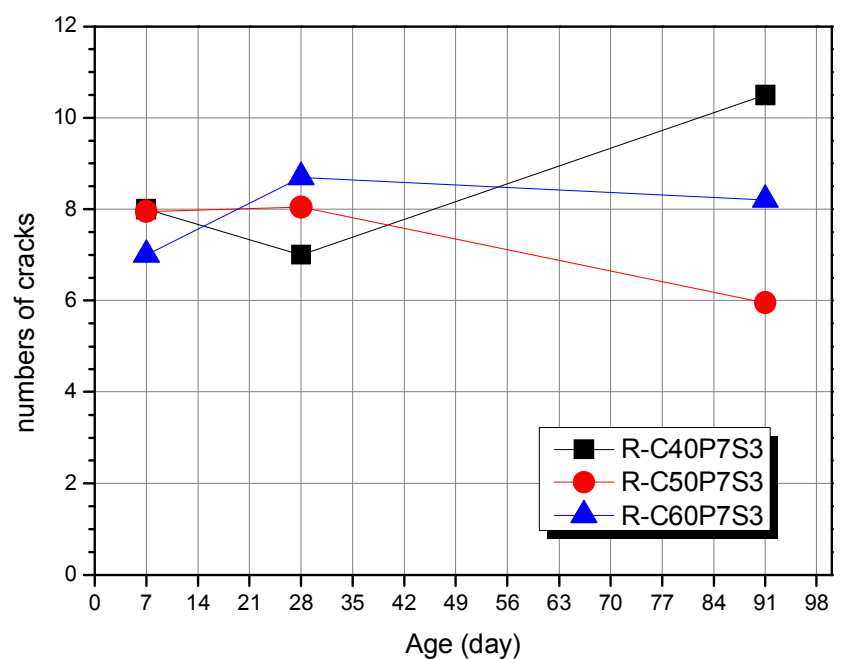

(e) Numbers of cracks

Figure 4. Relationship of flexural properties and age.

\subsubsection{Flexural Strength}

Figure 4 shows the mechanical properties of R-HFDFRC up to 91 days old and the number of cracks by results of 3point bending test. First, according to Figure 4(a), (b) and (c), flexural strength, and compressive fracture energy (average flexural stress up to $\delta=7.5 \mathrm{~mm}$ ) of R-HFDFRC up to 91 days increases with the passage of age when $\mathrm{W} / \mathrm{B}=50$ and $60 \%$.

On the other hand, $\mathrm{W} / \mathrm{B}=40 \%$ is the highest value in 28 days, and it is declining at 91 days. This is because the matrix strength of R-HFDFRC increased with the difference in W/B and the progress of age, but it became difficult to bridge effect with fibers. However, detailed examination is required in the future.

In addition, the fracture toughness of R-HFDFRC up to 91 days varies with the progress of age due to differences in $\mathrm{W} / \mathrm{B}$, but after 28 days, it is about $4 \mathrm{MPa}$ or more, indicating that it has sufficient flexural toughness. Next, according to Figure 4(d), the ultimate tensile stress of R-HFDFRC up to 91 days is the minimum at 28 days regardless of the difference in $\mathrm{W} / \mathrm{B}$, but it is more than $1 \%$ regardless of the difference in W/B and age. Finally, according to Figure 4(e), the number of cracks in R-HFDFRC up to 91 days is more than 6 cracks although the tendency with the progress of age varies due to differences in W/B. In other words, R-HFDFRC was found to have sufficient flexural toughness and crack dispersibility even at 91 days. From now on, it is necessary to examine in detail the effects of differences in W/B on the process of age according to factors mentioned above.

\subsection{Approximate Results of Strength}

\subsubsection{Compressive Strength}

For Fc and E of R-HFDFRC up to 91 days, concrete standards specification of Japan society of civil engineers (JSCE) and CEB-FIP Model Code 1990(MC90) try approximation with an approximate expression. [16-17]

From JSCE's formula

$$
\begin{gathered}
F_{c}(t)=F_{c}(28) t /(\alpha t+\beta) \\
E_{(t)}=\gamma \sqrt{F_{c}(t)}
\end{gathered}
$$

From MC90's formula

$$
\begin{gathered}
F_{c}(t)=\exp \left[s_{1}-(28 / t)^{1 / 2}\right] F_{c}(28) \\
E(t)=\sqrt{\exp \left[s_{1}-(28 / t)^{1 / 2}\right.} E(28)
\end{gathered}
$$

Here, $t$ : age, F28,E28: compressive strength (MPa) and Young's modulus (MPa) at 28 days, $\alpha, \beta, \gamma, s$ : material constant.

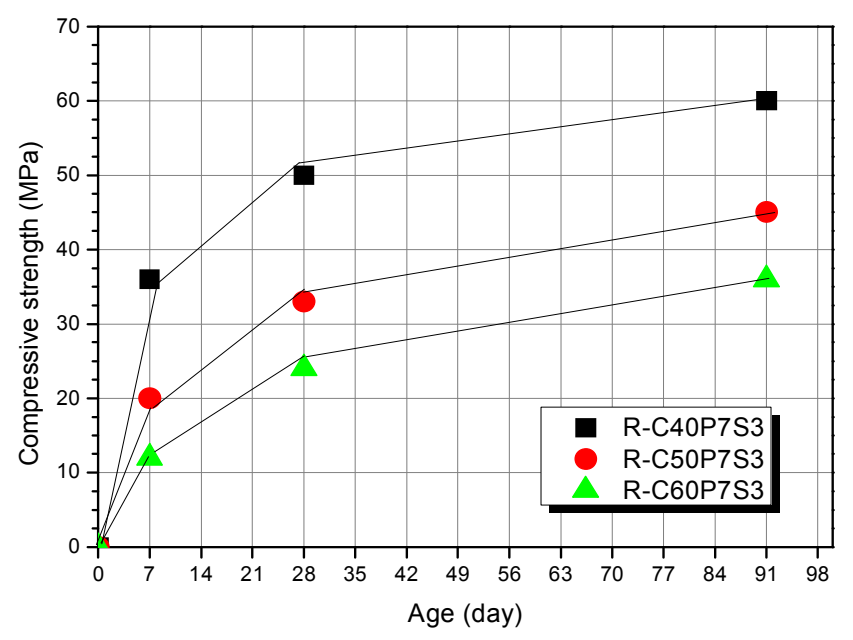

(a) Results by JSCE's formula

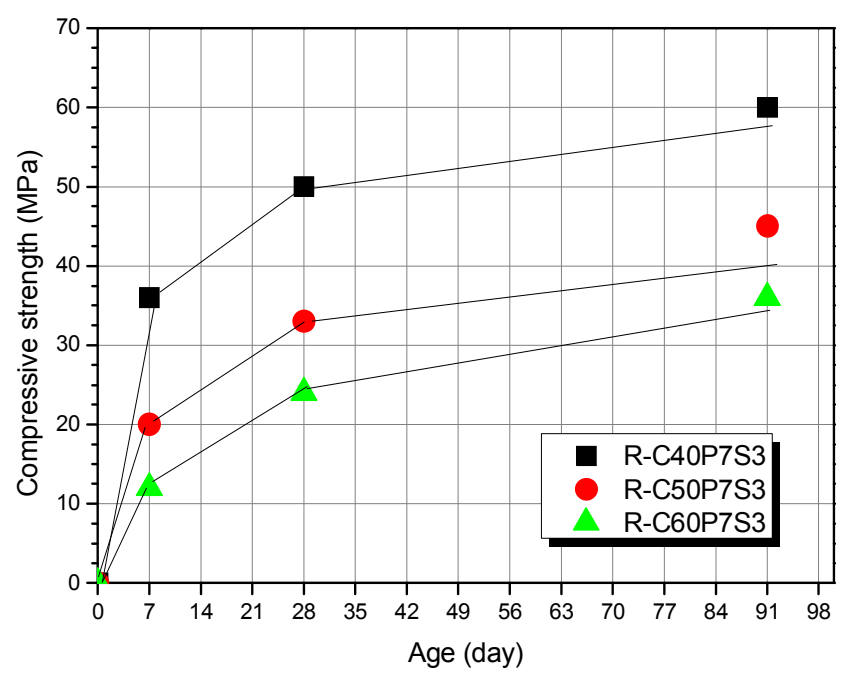

(b) Results by MC90's formula

Figure 5. Results of compressive strength by formulae.

Figure 5 and Figure 6 show the relation of age to Fc and $\mathrm{E}$ of R-HFDFRC obtained by uniaxial compressive test. In addition, the curves in the figure are approximate results of equations (3) to (6). According to results of equations, the approximate error of $\mathrm{Fc}$ by formula (3) to $-13.4 \%$, the approximate error of E by formula (4) to +5.94 to $-4.99 \%$, and the approximate error of Fc by formula (5) to $31.1 \%$, and the approximate error of formula (6) to $-12.1 \%$. Fc and $\mathrm{E}$ of RHFDFRC up to 91 days are generally approximate by expressions (3) to (6) regardless of the difference of W/B. However, in the case of Fc, the approximate error of seven 
days of material age is increased in the JSCE-based expression, and in the MC90-based expression, the approximate error of 91 days is increased. In the case of $\mathrm{E}$, the approximate error of 91 days is large for MC90-based formula.

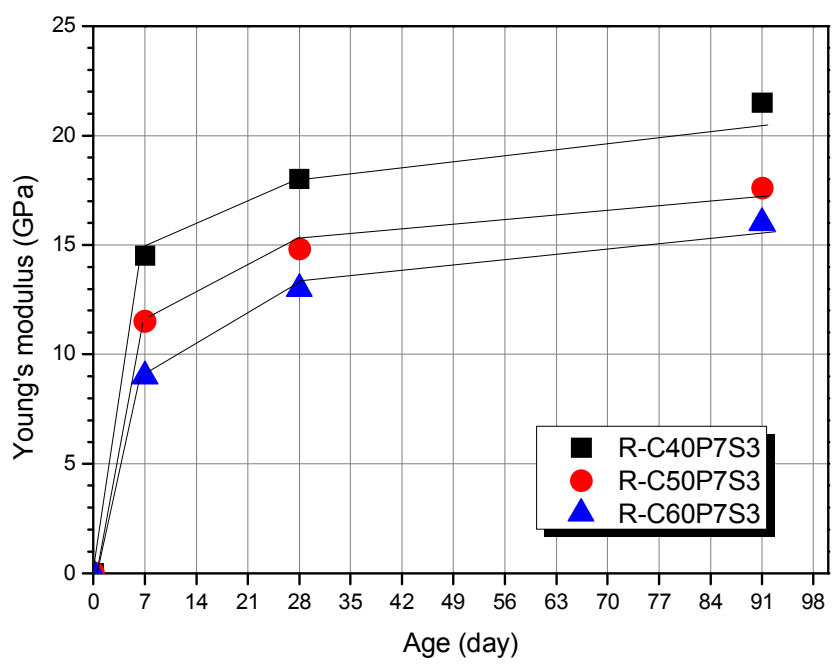

(a) Results by JSCE's formula

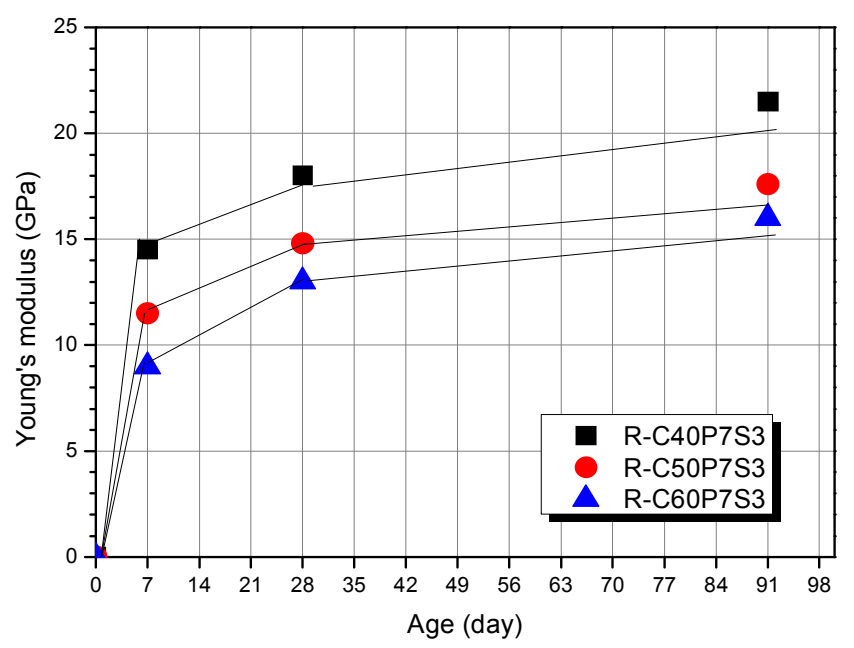

(b) Results by MC90's formula

Figure 6. Results of Young's modulus by formulae.

\subsubsection{Flexural Strength}

Figure 7 shows the relationship between flexural strength and tensile strength-compressive strength obtained by the uniaxial compressive test and the 3-point bending test of RHFDFRC.

In addition, the curves in the figure are approximate results according to the following formula, (7) and (8).

According to Figure $7(\mathrm{a})$, the flexural strengthcompressive strength relationship is generally approximated by a single curve. In addition, the tensile strengthcompressive strength relationship in Figure 7(b) is also considered to be approximate by a single curve. Flexural strength and tensile strength of concrete are generally represented as the power function of compressive strength. Therefore, in this study, we will try to approximate flexural strength and tensile strength of R-HFDFRC by the following approximate formula. [18]

$$
\begin{gathered}
f_{f b}=A \times F_{c}^{B} \\
f_{f t}=C \times F_{c}^{D}
\end{gathered}
$$

Here, $A, B, C$ and $D$ are material constants.

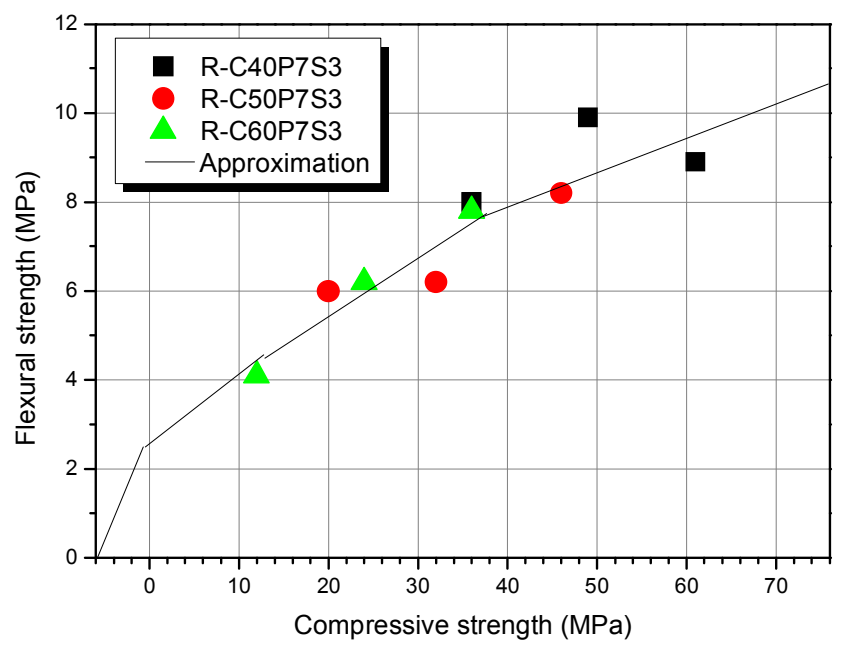

(a) Relationship between flexural strength and compressive strength

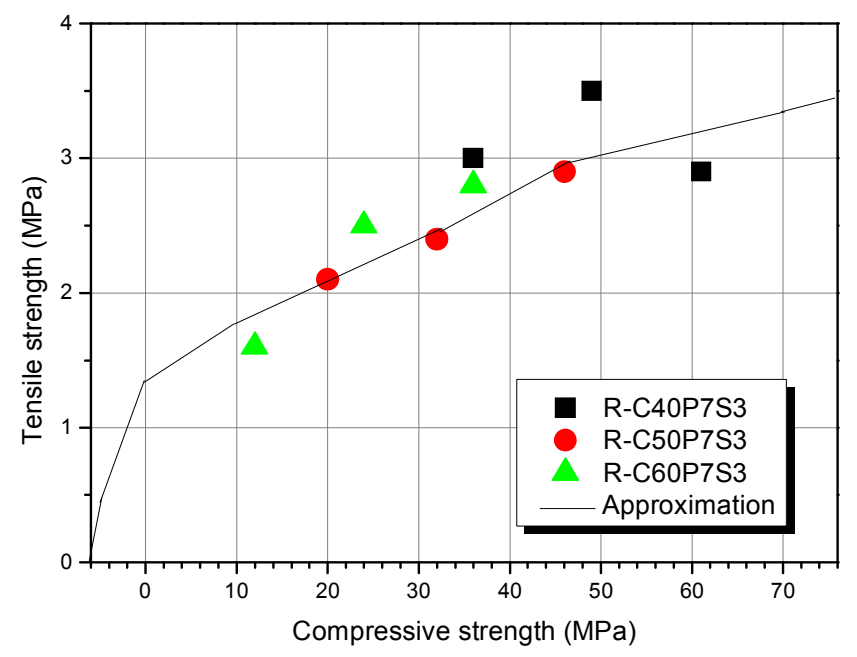

(b) Relationship between tensile strength and compressive strength

Figure 7. Approximation results by formula 7 and 8.

The approximate error of flexural strength by formula (7) to the result of the experiment up to 91 days is +10.7 to $9.28 \%$, and the approximate error of tensile strength by formula (8) is +19.0 to $-11.5 \%$. Flexural strength and tensile strength of each R-HFDFRC up to 91 days are approximate by formula (7) and (8) regardless of the difference of W/B.

In other words, it was found that there is a high possibility that flexural strength and tensile strength can be estimated from the compressive strength of various R-HFDFRCs according to the different ages.

However, since flexural strength and tensile strength of RHFDFRC tend to decrease when compressive strength exceeds 50MPa the range of application of this approximate expression should be more than $50 \mathrm{MPa}$ on compressive 
strength.

\subsubsection{Results of Shrinkage Test}

Figure 8 shows the change over time in shrinkage strain of HFDFRC obtained by a shrinkage test with a drying starting 7 days.

According to Figure 8, the shrinkage strain of R-HFDFRC at 70 days of drying age is lowest when $\mathrm{W} / \mathrm{B}=40 \%$ (RC40P7S3: $1789 \mu$ ), followed by $\mathrm{W} / \mathrm{B}=60 \%$ (R-C60P7S3: $1989 \mu$ ), and Finally, in case of $\mathrm{W} / \mathrm{B}=50 \%$ is $\mathrm{R}-\mathrm{C} 50 \mathrm{P} 7 \mathrm{~S} 3$ : $2132 \mu)$.

If we focus on the preparation in this study (see Table 1 above), the unit weight of water is the smallest when $\mathrm{W} / \mathrm{B}=40 \%$. Therefore, the shrinkage strain was minimized when $\mathrm{W} / \mathrm{B}=40 \%$.

In the case of $\mathrm{W} / \mathrm{B}=50$ and $60 \%$, the unit weight of water is about the same. However, the unit weight of coarse aggregate is $\mathrm{W} / \mathrm{B}=60 \%$ lager than $\mathrm{W} / \mathrm{B}=50 \%$. Therefore, the shrinkage strain is thought to be the largest when $\mathrm{W} / \mathrm{B}=50 \%$.

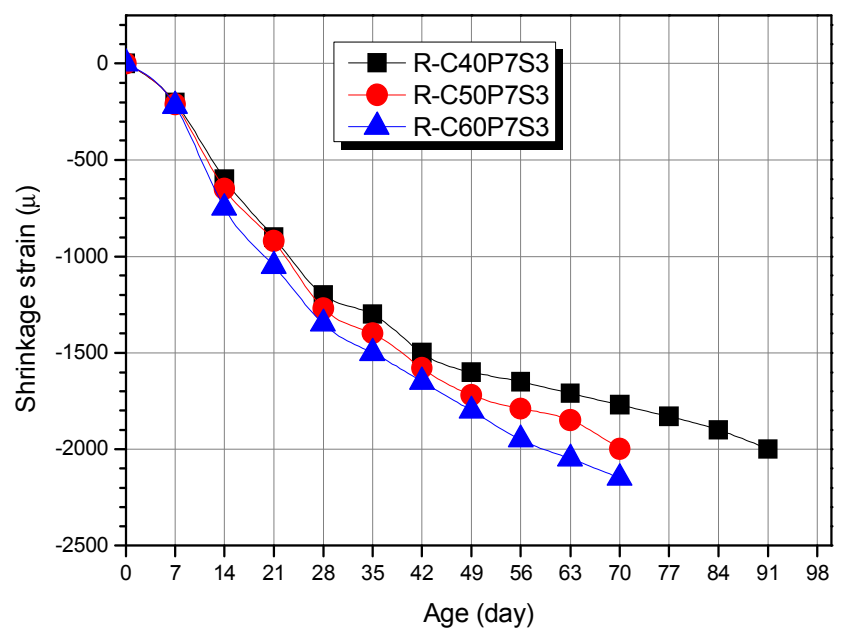

Figure 8. Results of shrinkage strain (HFDFRC).

Figure 9 obtained by shrinkage test with 7 days of drying age. It shows the aging of the shrinkage strain of the DFRM.

First, according to Figure 9(a), the shrinkage strain of R-M series at 420 days of drying age is the smallest when $\mathrm{W} / \mathrm{B}=40 \%$ : R-M40P10S0: $3470 \mu$ and then when $\mathrm{W} / \mathrm{B}=60 \%$ : R-M50PV10S0: $4048 \mu$, Finally, in case of $\mathrm{W} / \mathrm{B}=50 \%$ is $\mathrm{R}$ C50P7S3: $4072 \mu$.

If we focus on the preparation in this study (see Table 1 above), the unit weight of water is the smallest when $\mathrm{W} / \mathrm{B}=40 \%$. Therefore, the shrinkage strain was minimized when $\mathrm{W} / \mathrm{B}=40 \%$. Also, when $\mathrm{W} / \mathrm{B}=50 \%$ and $60 \%$, the unit weight of water is about the same.

However, the unit weight of fine aggregate (fine grain) is $\mathrm{W} / \mathrm{B}=60 \%$ larger than $\mathrm{W} / \mathrm{B}=50$, and it is thought that the shrinkage strain becomes the largest when $\mathrm{W} / \mathrm{B}=60 \%$ due to the influence of fine particles in the fine aggregate.

According to Figure 9(b), the shrinkage strain of RM50P10S0 and N-M50P10S0 on 420 days of drying age is R-M50P10S0 $(4048 \mu)$ larger than N-M50P10S0 (3740 $\mu)$. If we focus on the preparation in this study (see Table 1 above), the unit weight of water and fine aggregate of R-M50P10S0 and N-M50P10S0 are about the same.

However, if we pay attention to the physical properties of aggregates in this study (see Table 2), the surface dry density of fine aggregates is N-M50P10S0 larger than R-M50P10S0, the water absorption ratio is N-M50P10S0 larger than RM50P10S0. Therefore, it is thought that the shrinkage strain is R-M50P10S0 larger than N-M50P10S0.

Furthermore, the shrinkage strain of R-M50P10S0 and RM50P10S0 on 420 days of drying age is R-M50P10S0 $(4048 \mu)$ larger than R-M50P10S0 $(3945 \mu)$.

Focusing on the combinations in this study (see Table 1), used fine aggregate is medium and fine grain in $\mathrm{R}$ M50P10S0, and medium grain in R-M50P10S0. Due to the influence of fine grain in R-M50P10S0, the shrinkage strain is assumed to be R-M50P10S0 larger than R-M50P10S0.

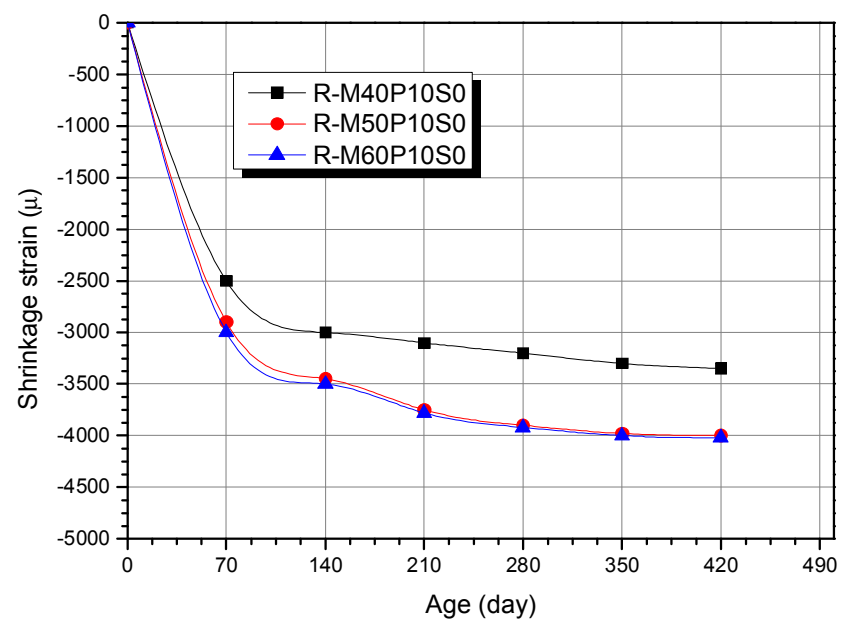

(a) Shrinkage strain according to the $\mathrm{W} / \mathrm{B}$

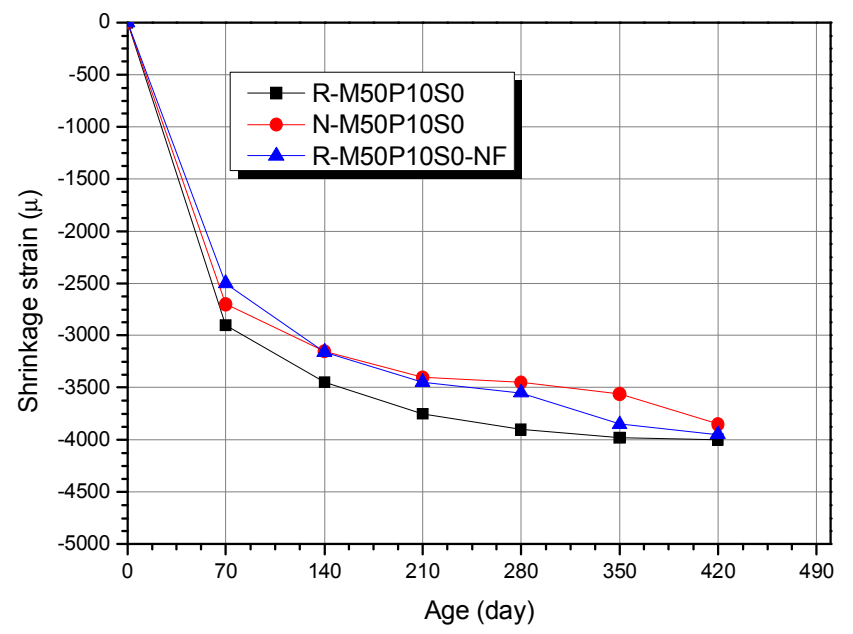

(b) Shrinkage strain according to the specimen types

Figure 9. Results of shrinkage strain (DFRM).

Figure 10 shows changes over time in shrinkage strain of HFDFRC and DFRM (W/B=50\%) obtained by a shrinkage test with a drying starting age of 7 days. First, according to Figure 10(a), the shrinkage strain of R-C50P7S3 and RC50P10S0 at 49 days of drying age is R-C50P10S0 (1997 $\mu)$ larger than R-FC50V7S3 $(1815 \mu)$. It was found that by 
mixing steel fiber as a reinforcing fiber, shrinkage strain can be reduced by $182 \mu$.

According to Figure 10(b), the shrinkage strain of RC50P10S0 and R-M50P10S0 on 49 days of drying age is RM50P10S0 $(2443 \mu)$ larger than R-C50P10S0 $(1997 \mu)$. With the addition of coarse aggregate, it was found that the shrinkage strain was reduced by $446 \mu$ by reducing mortar paste.

In other words, by mixing steel fiber and coarse aggregate into HFDFRM, it has been found that shrinkage strain can be greatly reduced.

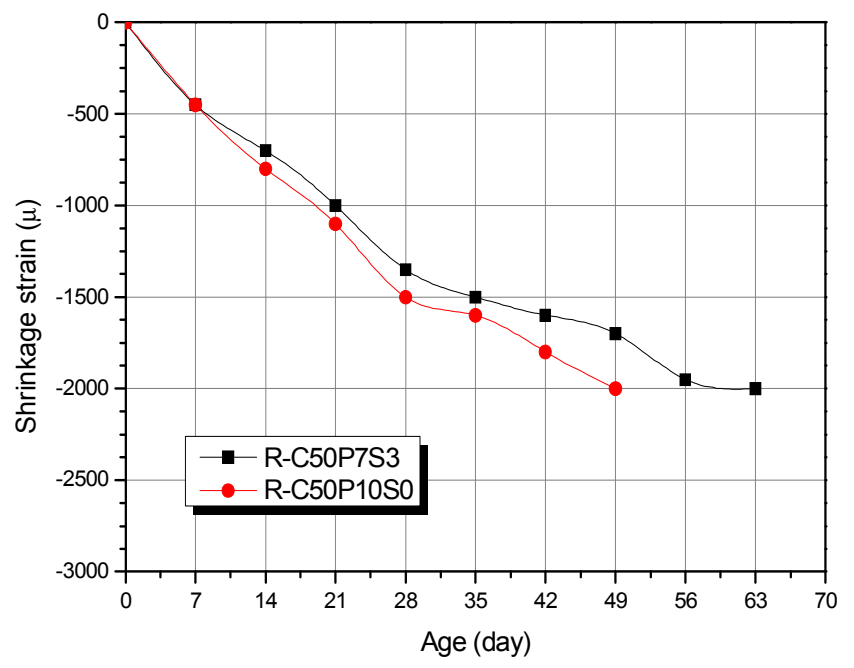

(a) Shrinkage strain according to the fiber fractions

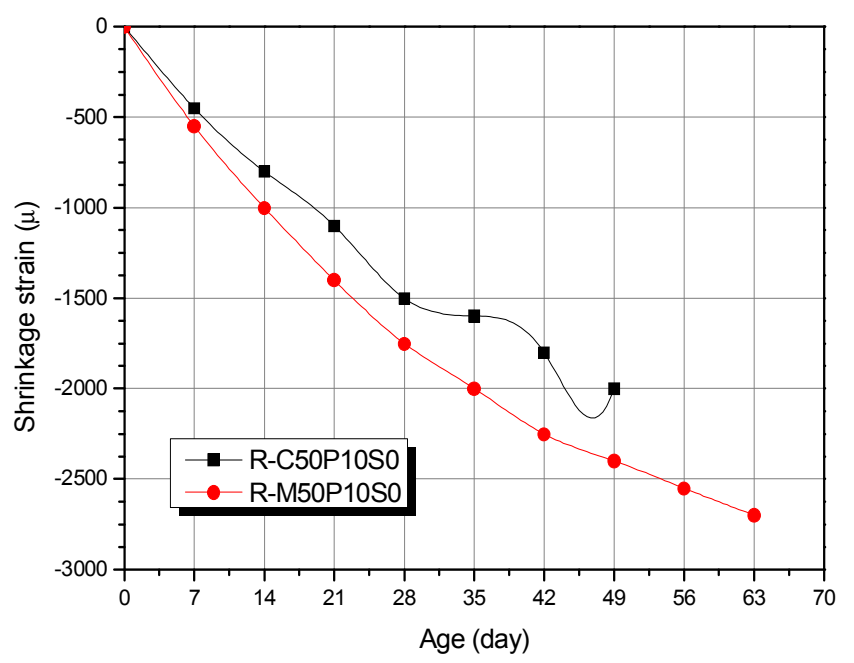

(b) Shrinkage strain according to the matrix

Figure 10. Results of shrinkage strain (HFDFRC and HFDFRM).

\section{Conclusions}

The conclusions obtained within the scope of this research are shown below.

1) High fluidity and high toughness concrete made from recycled fine and coarse aggregate has sufficient flexural toughness and crack dispersibility even at 91 days.

2) From the results of expression of compressive strength and long-term strength of Young's modulus of high fluidity and high toughness concrete using recycled fine and coarse aggregate, it can be approximated from the experimental formula shown in this study.

3) There is a high possibility that flexural strength and tensile strength can be estimated from the compressive strength of high flow and high toughness concrete using recycled fine and coarse aggregate of different ages within the range of $50 \mathrm{MPa}$ or less.

4) By mixing steel fibers and recycled coarse aggregate into high flow and high toughness cement composite materials using recycled fine aggregate, shrinkage strain can be greatly reduced.

\section{Acknowledgements}

This paper was supported by Joongbu University Research \& Development Fund in 2020 (Grant No. JURD-2020). The authors would like to thank the Joongbu University.

\section{References}

[1] JCI (2002), "Research Committee Report on Performance Evaluation and Structural use of High-Toughness Cement Composites," Research Committee on Performance Evaluation and Structural use of High-Toughness Cement Composites, 1-10.

[2] JCI (2009), "Report of Research Committee on the Utilization of High-Strength and High-Toughness Concrete," Research Committee on the Utilization of High-Strength and HighToughness Concrete, 74-85.

[3] Almusallam T., et al. (2016), "Analytical and Experimental Investigations on the Fracture Behavior of Hybrid Fiber Reinforced Concrete" Cement and Concrete Composites 74 (1), 201-217.

[4] Kim N. W., et al. (1998), "Crack resistance of hybrid fiber reinforced concrete," J. Japan Cement Association, 48 (1), 396-397.

[5] Watanabe K, (2017), "Mechanical properties of highly fluid fiber reinforced concrete using recycled aggregate", Proceedings of JCI, 39 (1), 271-276.

[6] Lee, J. H. (2017), "Influence of Concrete Strength Combined with Fiber Cement in the Residual Flexural Strengths of Fiber Reinforced Concrete" Composites Structures 168 (1), 216-225.

[7] Kochov, K., et al. (2020). "Using alternative waste coir fibres as a reinforcement in cement-fibre composites." Construction and Building Materials, 231, 351-358.

[8] Morishima, S., et al. (2020), "Influence of Fiber Type on Fundamental Mechanical Properties of Slurry Infiltrated Fiber Concrete" Cement Science and Concrete Technology, 73 (1), 311-316.

[9] Yang, I. H., et al, (2016), "Effect of Recycled Coarse Aggregate on Compressive Strength and Mechanical Properties of Concrete" Journal of KCI, 28 (1), 105-113.

[10] Miura Y. et al. (2010), "Tensile softening behavior of hightough cement composite materials using various fine aggregates" Proceedings of JCI, 32 (1), 287-292. 
[11] Kim, N. W., et al, (2020), Shrinkage Study of Concrete Considering Kinds of Coarse Aggregates" Journal of KCI, 32 (1), 95-102.

[12] Onomoto, K., et al., (2020), "A Study on Creep Property of Concrete with Recycled Aggregate and Fly ash" Journal of Structural and Construction Engineering, 85, 311-319.

[13] Watanabe, S., et al., (2017), "Study on Influence of Coarse Aggregate on Young's Modulus of High Strength Concrete" Journal of Structural and Construction Engineering, 82, 321327.

[14] Natalia, V., et al., (2019), "'Improved Method to Measure the
Strength and Elastic Modulus of Single Aggregate Particles" Materials and Structures, 53, 77-84.

[15] JCI Standards (2007), "Bending moment-curvature curve test method, JCI-S-003-2007, 8-10.

[16] JSCE, (1999), "The method for testing bending strength and bending toughness of JSCE-G552 fiber-reinforced concrete", Concrete Standards Guide, 217-219.

[17] CEB, (1990), "CEB - FIP MODEL CODE 1990", Thomas Telford Co., 45-56.

[18] JSCE, (1996), "Concrete Standards Guide", Construction Edition, 190-191. 